\title{
Roles and practices of general practitioners and psychiatrists in management of depression in the community Sophie Tardieu*1,2, Alain Bottero ${ }^{3}$, Patrick Blin ${ }^{4}$, Michael Bohbot ${ }^{5}$, Sylvia Goni ${ }^{5}$, Alain Gerard ${ }^{3}$ and Isabelle Gasquet ${ }^{6,7}$
}

\begin{abstract}
Address: ${ }^{1}$ Medical Evaluation Department, Assistance Publique-Hôpitaux de Marseille, Marseille, France, ${ }^{2}$ Public Health Department, EA 3279 , Faculté de Médecine, Marseille, France, ${ }^{3}$ Paris, ${ }^{4}$ Pharmacology Department, Université Victor Segalen Bordeaux 2, Bordeaux, France, ${ }^{5}$ LundbeckFrance, Paris, ${ }^{6}$ National Institute of Health and Medical Research, INSERM-U 669 Paris, France and ${ }^{7}$ Direction de la Politique médicale, Assistance Publique - Hôpitaux de Paris, Paris, France
\end{abstract}

Email: Sophie Tardieu* - sophie.tardieu@ap-hm.fr; Alain Bottero - verbot@wanadoo.fr; Patrick Blin - patrick.blin@pharmaco.u-bordeaux2.fr; Michael Bohbot - mboh@lundbeck.com; Sylvia Goni - SYGO@Lundbeck.com; Alain Gerard - al.gerard@free.fr;

Isabelle Gasquet - isabelle.gasquet@sap.ap-hop-paris.fr

* Corresponding author

Published: 30 January 2006

BMC Family Practice 2006, 7:5 doi:10.1 186/147|-2296-7-5
Received: 20 June 2005

Accepted: 30 January 2006

This article is available from: http://www.biomedcentral.com/I47/-2296/7/5

(C) 2006 Tardieu et al; licensee BioMed Central Ltd.

This is an Open Access article distributed under the terms of the Creative Commons Attribution License (http://creativecommons.org/licenses/by/2.0), which permits unrestricted use, distribution, and reproduction in any medium, provided the original work is properly cited.

\begin{abstract}
Background: Little is known about depressed patients' profiles and how they are managed. The aim of the study is to compare GPs and psychiatrists for $1^{\circ}$ ) sociodemographic and clinical profile of their patients considered as depressed $2^{\circ}$ ) patterns of care provision.
\end{abstract}

Methods: The study design is an observational cross-sectional study on a random sample of GPs and psychiatrists working in France. Consecutive inclusion of patients seen in consultation considered as depressed by the physician. GPs enrolled 6, I04 and psychiatrists I,433 patients. Data collected: sociodemographics, psychiatric profile, environmental risk factors of depression and treatment. All clinical data were collected by participating physicians; there was no direct independent clinical assessment of patients to check the diagnosis of depressive disorder.

Results: Compared to patients identified as depressed by GPs, those identified by psychiatrists were younger, more often urban $(I 0.5 \% \vee 5.4 \%-O R=2.4)$, educated $(42.4 \% \vee 25.4 \%-O R=3.9)$, met DSM-IV criteria for depression $(94.6 \% \vee 85.6 \%-O R=2.9)$, had been hospitalized for depression $(26.1 \%$ v $15.6 \%-O R=2.0)$ and were younger at onset of depressive problems (all adjusted $p<.00 \mathrm{I}$ ). No difference was found for psychiatric and somatic comorbidity, suicide attempt and severity of current depression.

Compared to GPs, psychiatrists more often prescribed tricyclics and very novel antidepressants $(7.8 \%$ v $2.3 \%$ OR $=5.0$ and $6.8 \%$ v $3.0 \% O R=3.8)$ with longer duration of antidepressant treatment. GPs' patients received more "non-conventional" treatment $(8.8 \% \vee 2.4 \% \mathrm{OR}=0.3)$ and less psychotherapy $(72.2 \% \vee 89.1 \%$ OR $=3.1)$ (all adjusted $p<.001)$.

Conclusion: Differences between patients mainly concerned educational level and area of residence with few differences regarding clinical profile. Differences between practices of GPs and psychiatrists appear to reflect more the organization of the French care system than the competence of providers. 


\section{Background}

Depression is a highly prevalent disorder associated with enormous personal and societal cost [1] The global burden of mental illness is expected to rise sharply over the coming decades. The WHO Global Burden of Disease Study estimates that by 2020, major depression will rank as the second cause of disability[2] There is general agreement in European community studies that the current (12-month) prevalence rate for major depressive disorder is approximately 6\%[3] Excluding hypertension, depression is commoner in primary care settings than any other condition. An average prevalence rate of $10.4 \%$ for current depressive episode (ICD-10) was reported by the WHO study of consecutive presenters in primary care[4]

In the health care system overall, GPs play a key role in diagnosing and treating patients with depressive disorders [5-7].

From the 1980s, numerous well-designed studies have reported that major depressive disorder is under-diagnosed and under-treated by GPs. [8-10] In comparison to the extensive literature on detection and diagnosis of depression, little is known about depressed patients' profiles and how they are actually treated outside the USA and the UK. To design quality improvement programs, information is urgently needed about current practices and the reasons for variation in "real life" settings.

The present observational study aimed to compare GPs and private psychiatrists $1^{\circ}$ ) for sociodemographic and clinical profile of their patients seen in consultation and considered as depressed by GPs (PDGPs) and psychiatrists (PDPs) $2^{\circ}$ ) for patterns of care provision for these patients.

\section{Methods}

\section{Study design and sample}

1,815 psychiatrists and 9,593 GPS were personally approached in their practices. They were randomly selected from a national database of 4,330 private psychiatrists and 51,421 GPs. Among these, 361 private psychiatrists and 2,570 GPs agreed to participate (participation rate $26.8 \%$ and $19.9 \%$, respectively).

Over a 3-month inclusion period, psychiatrists were asked to include prospectively the first five consecutive patients considered as depressed seen in consultation and GPs were asked to include prospectively the first three consecutive patients identified as depressed. Inclusion criteria were: patients considered as depressed by the practitioner (this means no direct independent clinical assessment of the patient (by the physician in charge) to check the diagnosis of depressive disorder), age 18 plus, ongoing depressive disorder, and patients with episodes of depression at any stage of treatment. Patients were included whether or not the physician prescribed treatment for depression. (84.5\% of participating psychiatrists and $84.6 \%$ of participating GPs included at least one patient). Between September 2002 and February 2003, these practitioners enrolled 1,433 and 6104 patients respectively. The mean number of patients enrolled was $4.8(\mathrm{sd}=0.69)$ for psychiatrists and $2.5(\mathrm{sd}=0.41)$ for GPs.

Three groups of practitioners were considered: $1^{\circ}$ ) eligible practitioners that included patients, $2^{\circ}$ ) eligible practitioners that did not include patients and $3^{\circ}$ ) eligible practitioners that did not participate to the study. The comparison of these three groups showed over-representation of female GPs, under-representation of physicians in the Paris region and over-representation of practitioners in western regions of France (for both GPs and psychiatrists), and the Mediterranean region (psychiatrists only) in group 1. No other differences were detected (Table 1).

\section{Data collected}

All clinical data were collected by participating physicians; there was no direct independent clinical assessment by the physician in charge of the patient to check the diagnosis of depressive disorder. The physicians recorded selected cases on anonymous patient record forms. Information gathered was divided into thee domains:

1) Patient socio-demographic variables: gender, age, marital status, area of residence, living arrangements, professional status, educational status, and income level.

2) Present and past clinical profile, using DSM-IV criteria for major depressive disorders [11] interspersed with other symptoms, and also alcohol dependency, bipolar disorder, anxiety disorder, suicide attempts, hospitalization for depressive problems, past episode of depressive disorder and age at first depressive episode. The severity of the depressive disorders was evaluated with the CGI-severity scale(.)[12] A list of significant stressful events that might contribute to the depressive episode was also proposed.

3) Type of care provided for the current depressive episode (psychotropics, psychotherapy, non conventional treatment, concomitant care by another health professional) and how long the patient had been in care.

According to the French ethics committee procedures, the protocol was submitted to the national medical association committee (CNOM) and to the national committee for protection of individual privacy (CNIL). Before including a patient, the physician was required to provide an information letter to obtain informed consent. 
Table I: Description of the eligible practitioners

\begin{tabular}{|c|c|c|c|c|c|c|c|c|}
\hline & \multicolumn{4}{|c|}{ Eligible GPs } & \multicolumn{4}{|c|}{ Eligible psychiatrists } \\
\hline & \multicolumn{2}{|c|}{ participants } & \multirow{2}{*}{$\begin{array}{c}\text { non- } \\
\text { participant }\end{array}$} & & \multicolumn{2}{|c|}{ participants } & \multirow{2}{*}{$\begin{array}{c}\text { non- } \\
\text { participant }\end{array}$} & \\
\hline & $\begin{array}{l}\text { at least one } \\
\text { patient }\end{array}$ & $\begin{array}{l}\text { no patient } \\
\text { included }\end{array}$ & & & $\begin{array}{l}\text { at least one } \\
\text { patient }\end{array}$ & $\begin{array}{l}\text { no patient } \\
\text { included }\end{array}$ & & \\
\hline & $n=2175$ & $\mathrm{n}=395$ & $N=7021$ & $\mathrm{P}^{*}$ & $\mathrm{n}=305$ & $\mathrm{n}=56$ & $N=1454$ & $\mathrm{P}^{*}$ \\
\hline $\begin{array}{l}\text { Distribution within the type of } \\
\text { practitioner (\%) }\end{array}$ & 22.7 & 4.1 & 73.2 & & 16.8 & 3.1 & 80.1 & \\
\hline Female gender $(\%)$ & 20.7 & 14.1 & na & 0.003 & 38.3 & 26.3 & na & 0.09 \\
\hline Regional distribution (\%) & & & & $<0.001$ & & & & $<0.001$ \\
\hline Paris, surrounding departments & 9.7 & 13.2 & 14.8 & & 21.0 & 22.4 & 27.5 & \\
\hline Paris basin & 13.7 & 16.7 & 18.3 & & 10.2 & 19.0 & 14.4 & \\
\hline East & 11.5 & 10.4 & 12.2 & & 8.9 & 8.6 & 12.6 & \\
\hline North-east & 10.9 & 6.1 & 8.5 & & 5.6 & 5.2 & 7.7 & \\
\hline North & 6.2 & 6.1 & 6.3 & & 6.9 & 6.9 & 3.3 & \\
\hline West & 17.6 & 8.9 & 13.6 & & 13.1 & 6.9 & 11.2 & \\
\hline South-west & 15.7 & 19.7 & 12.3 & & 14.4 & 10.3 & 10.1 & \\
\hline Mediterranean region & 14.6 & 19.0 & 14.0 & & 20.0 & 20.7 & 13.2 & \\
\hline Age (\%) & & & na & 0.16 & & & na & 0.46 \\
\hline 40 years and less & 20.8 & 16.7 & & & 11.1 & 5.7 & & \\
\hline $4 I-50$ years & 48.3 & 49.0 & & & 48.3 & 49.1 & & \\
\hline 50 years and more & 30.8 & 34.3 & & & 40.6 & 45.3 & & \\
\hline $\begin{array}{l}\text { Mean \# of years of private } \\
\text { practice (sd) }\end{array}$ & $17.4(8.3)$ & $17.7(7.8)$ & na & 0.51 & $16.1(7.2)$ & $15.6(6.8)$ & na & 0.67 \\
\hline $\begin{array}{l}\text { Mean \# of patient consultations } \\
\text { per month (sd) }\end{array}$ & $\begin{array}{l}468.6 \\
(210.1)\end{array}$ & $\begin{array}{l}526.7 \\
(216.5)\end{array}$ & na & 0.08 & $302(240.0)$ & na & na & - \\
\hline $\begin{array}{l}\text { Proportion of depressed } \\
\text { patient/overall patient of the } \\
\text { physician }\end{array}$ & & & na & 0.19 & & na & na & - \\
\hline$\leq 5$ & 15.5 & 12.0 & & & 0.0 & & & \\
\hline $6-10$ & 43.5 & 32.0 & & & 2.0 & & & \\
\hline $11-20$ & 33.3 & 36.0 & & & 5.6 & & & \\
\hline $21-30$ & 4.3 & 12.0 & & & 12.3 & & & \\
\hline $31-40$ & 2.5 & 8.0 & & & 23.3 & & & \\
\hline $4 I-50$ & 0.5 & 0.0 & & & 20.9 & & & \\
\hline$>50$ & 0.3 & 0.0 & & & 35.9 & & & \\
\hline
\end{tabular}

* chi2 test, comparison of participants having included at least one patient $v$ participants not having included any patient $v$. non participants (if data available),

na: data non available

\section{Statistical analysis}

Psychiatrists were compared to GPs using logistic regression adjusted on patient gender and age. For variables related to care patterns, analyses were also adjusted on CGI score. As it was not possible to consider the "centre" (practitioner) effect in the logistic regressions in these models (the variable "centre" is nested in the dependent variable "psychiatrist v. GP"), other analyses were previously conducted in order to detect any " cluster effect " since each practitioner included several patients. Two additional logistic models were used with each of the criteria (sociodemographic profile, clinical status, life events, and medical care). The only variable not tested was "geographic area" because it was nested in the variable "centre".

In the two models the criterion was the dependent (binary) variable with the following effects tested: age, gender and CGI-score for medical care, type of respondent (psychiatrists versus GPs). In the first model the variable "centre" (as a random effect) was added but not in the second model. The P values obtained for the variable "psychiatrist v. GP" on each model were compared. They were all very similar. 
Table 2: Comparison of sociodemographic profile of GPs' depressed patient and psychiatrists' depressed patient $(n=7537)$

\begin{tabular}{|c|c|c|c|}
\hline & $\begin{array}{c}\text { GPs' patients } \\
n=6104 \\
n(\%)\end{array}$ & $\begin{array}{c}\text { Psychiatrists' patients } \\
\mathrm{n}=1433 \\
\mathrm{n}(\%)\end{array}$ & $\mathrm{P}$ value * \\
\hline Age & & & $<0.001$ \\
\hline$<30$ years & $68 \mid(11.2)$ & $206(14.4)$ & \\
\hline $31-40$ years & $1390(22.90)$ & $346(24.2)$ & \\
\hline $4 I-50$ years & $1607(26.5)$ & $443(31.0)$ & \\
\hline $5 \mathrm{I}-60$ years & $1210(19.9)$ & $314(21.9)$ & \\
\hline$>60$ years & $1186(19.5)$ & $122(8.5)$ & \\
\hline \multirow[t]{2}{*}{ Female gender } & 4367 (7I.7) & $1004(70.1)$ & 0.22 \\
\hline & & & OR [IC95] ** \\
\hline \multicolumn{4}{|l|}{ Marital status } \\
\hline Single & $779(12.8)$ & $270(18.9)$ & 1.0 \\
\hline Married, living with partner & $3695(60.9)$ & $84 \mid(58.8)$ & $0.80[0,68-0.94]$ \\
\hline Separated or divorced Widowed & $1598(26.3)$ & $319(22.3)$ & $0.77[0,63-0,95]$ \\
\hline \multicolumn{4}{|l|}{ Living Arrangement } \\
\hline Living alone & $1368(22.5)$ & $337(23.5)$ & 1.0 \\
\hline Living with I person & $1568(25.8)$ & $386(27.0)$ & $1.01[0,86-1,19]$ \\
\hline Living with $\geq 2$ persons & $3137(51.7)$ & $708(49.5)$ & $0.80(0,69-0,93]$ \\
\hline \multicolumn{4}{|l|}{ Geographic area } \\
\hline Rural $(<50000)$ & $4164(69.0)$ & $742(52.5)$ & 1,0 \\
\hline Urban $(>50000)$ & $1544(25.6)$ & $523(37.0)$ & $1,89[1.67-2.15]$ \\
\hline Paris region & $326(5.4)$ & $148(10.5)$ & $2.44[1.98-3.01]$ \\
\hline \multicolumn{4}{|l|}{ Profession } \\
\hline Never worked & $521(8.8)$ & $99(7.0)$ & 1.0 \\
\hline Farmer & $213(3.6)$ & $28(2.0)$ & $0.86[0.54-1.35]$ \\
\hline Trade, commerce, artisan & $428(7.2)$ & $59(4.2)$ & $0.78[0.55-1.11]$ \\
\hline Managerial, I professional & $711(12.0)$ & $290(20.5)$ & $2.11[1.63-2.74]$ \\
\hline Intermediate Professions) & $1243(21.0)$ & $416(29.3)$ & $1.73[1.35-2.21]$ \\
\hline Executives & $2032(34.3)$ & $434(30.6)$ & $1.10[0.87-1.40]$ \\
\hline Worker & $769(13.0)$ & $92(6.5)$ & $0.64[0.47-0.87]$ \\
\hline \multicolumn{4}{|l|}{ Occupation } \\
\hline Employed & $3536(58.3)$ & $943(65.8)$ & 1.0 \\
\hline Unemployed & $533(8.8)$ & $122(8.5)$ & $0.85[0.69-1.05]$ \\
\hline Retired & 1194 (19.7) & $14 \mid(9.8)$ & $0.55[0.43-0.70]$ \\
\hline Homemaker & $518(8.5)$ & $92(6.4)$ & $0.72[0.56-0.91]$ \\
\hline Student & III (I.8) & $53(3.7)$ & $1.52[1.06-2.17]$ \\
\hline Other & $170(2.8)$ & $82(5.7)$ & $1.94[1.47-2.57]$ \\
\hline \multicolumn{4}{|l|}{ Educational level } \\
\hline Primary & $926(15.9)$ & $82(5.8)$ & 1,0 \\
\hline Lower secondary & $1854(31.9)$ & $353(25.1)$ & $1.94[1.50-2.51]$ \\
\hline Upper secondary & 1564 (26.9) & $376(26.7)$ & $2.39[1.85-3.10]$ \\
\hline Higher education & $1477(25.4)$ & $598(42.4)$ & $3.95[3.06-5.09]$ \\
\hline \multicolumn{4}{|l|}{ Income } \\
\hline Destitute & $83(1.4)$ & $19(1.3)$ & 1,0 \\
\hline Low & $1119(18.5)$ & $228(16.0)$ & $0.98[0.58-1.65]$ \\
\hline Moderate & 3569 (58.9) & $830(58.2)$ & $1.14[0.69-1.89]$ \\
\hline High & $1291(21.3)$ & $350(24.5)$ & I.4I $[0.84-2.36]$ \\
\hline
\end{tabular}

In bold: statistically significant odds ratio $(\mathrm{p}<0.05)$ and less than 0.5 or higher than 2.0

* Chi2 test

** GPs' patients are the reference, odd ratio adjusted on gender and on age as a quantitative variable

Because of the large sample, a small difference in percentage was statistically significant. Therefore odd-ratios equal to or higher than 2 or equal to or lower than 0.5 were retained as being clinically relevant, these values being classically used in epidemiological studies.
Statistical analysis was performed using $\mathrm{SAS}^{\circledast}$ software (version 8.2). 
Table 3: Comparison of clinical status and past history between GPs' patients and psychiatrists' patients $(n=7537)$

\begin{tabular}{|c|c|c|c|}
\hline & $\begin{array}{c}\text { GPs' patients } \\
\text { n }=6104 \\
n(\%)\end{array}$ & $\begin{array}{c}\text { Psychiatrists' patients } \\
n=1433 \\
n(\%)\end{array}$ & OR $[\mathrm{IC} 95]^{*}$ \\
\hline \multicolumn{4}{|c|}{ Status at the time of the clinical diagnosis of the current depressive episode } \\
\hline \multicolumn{4}{|l|}{ DSM-IV diagnosis of MDD } \\
\hline Yes & $5223(85.6)$ & $1355(94.6)$ & $2.91[2.28-3.70]$ \\
\hline No & $880(14.4)$ & $77(5.4)$ & 1.0 \\
\hline \multicolumn{4}{|l|}{$\begin{array}{l}\text { Number of symptoms of MDD on } \\
\text { criterion } A^{* *}\end{array}$} \\
\hline $5-6$ & $2397(45.9)$ & $416(30.7)$ & 1.0 \\
\hline $7-9$ & $2826(54.1)$ & $939(69.3)$ & $1.90[1.67-2.16]$ \\
\hline \multicolumn{4}{|l|}{ CGI-severity } \\
\hline Normal to moderately ill & $1350(22.8)$ & $215(15.1)$ & 1.0 \\
\hline Markedly to among the most ill & $4562(77.2)$ & $1207(84.9)$ & $1.67[1.43-1.97]$ \\
\hline \multicolumn{4}{|l|}{ Psychiatric antecedents } \\
\hline \multicolumn{4}{|l|}{ Past depressive episode } \\
\hline Yes & $3068(51.8)$ & $836(58.8)$ & $1.43[1.27-1.61]$ \\
\hline No & $2853(48.2)$ & $585(4 I .2)$ & 1.0 \\
\hline \multicolumn{4}{|l|}{$\begin{array}{l}\text { Hospitalization for depressive } \\
\text { problem }\end{array}$} \\
\hline Yes & $940(15.6)$ & $371(26.1)$ & $2.03[1.77-2.34]$ \\
\hline No & $5076(84.4)$ & $1050(73.9)$ & 1.0 \\
\hline \multicolumn{4}{|l|}{ Suicide attempt } \\
\hline Yes & $665(11.1)$ & $258(18.2)$ & $1.73[1.48-2.03]$ \\
\hline No & $5312(88.9)$ & $1161(81.8)$ & 1.0 \\
\hline \multicolumn{4}{|l|}{ Bipolar disorder } \\
\hline Yes & $295(4.9)$ & $107(7.5)$ & $1.70[1.35-2.15]$ \\
\hline No & $5703(95.1)$ & $1311(92.5)$ & 1.0 \\
\hline \multicolumn{4}{|l|}{ Alcohol dependence } \\
\hline Yes & $613(10.2)$ & $137(9.6)$ & $0.93[0.76-1.14)$ \\
\hline No & $5412(89.8)$ & $1284(90.4)$ & 1.0 \\
\hline \multicolumn{4}{|l|}{ Anxiety disorder } \\
\hline Yes & $4798(79.5)$ & $1050(74.3)$ & $0.76[0.67-0.87]$ \\
\hline No & $1239(20.5)$ & $363(25.7)$ & 1.0 \\
\hline \multicolumn{4}{|l|}{$\begin{array}{l}\text { Current chronic somatic disorder } \\
\text { **** }\end{array}$} \\
\hline Yes & $2830(47.5)$ & $500(35.8)$ & $0.72[0.63-0.83]$ \\
\hline No & $3123(52.5)$ & $898(64.2)$ & 1.0 \\
\hline
\end{tabular}

In bold: statistically significant odds ratio $(\mathrm{p}<0.05)$ and less than 0.5 or higher than 2.0

* GPs' patient are the reference, odd ratio adjusted on gender and on age as a quantitative variable

** Excluding patient with no MDD diagnosis. Criteria $A$ are depressed mood (AI), anhedonia (A2), weight loss when no dieting or weight gain (A3), insomnia or hypersomnia (A4), psychomotor agitation or retardation (A5), fatigue or loss of energy (A6), feeling of worthlessness or guilt (A7), diminished ability to think or concentrate (A8), suicidal behavior (A9)

**** Neurological, cardiovascular, pulmonary, hepato-gastro-enterological, endocrinological and others (including cancer)

\section{Results}

\section{Sociodemographic profile (Table 2)}

The PDPs were younger than the PDGPs (44.3 years, $\mathrm{sd}=$ $12.3 \mathrm{v}$. 47.9 years $\mathrm{sd}=14.9, \mathrm{p}=<.001)$. The biggest difference appeared in the over 60 s with twice the proportion of these patients in the PDGP compared to the PDP group.

PDPs more often lived in urban areas than PDGPs. For patients living in the Paris region, the likelihood of con- sulting a psychiatrist rather than a GP was 2.5 times greater. The distance covered to get to the consultation was much greater for PDP than for PDGP, with $62.7 \%$ of PDPs taking less than half hour to reach the consultation v. 90.7\% of PDGPs ( $\mathrm{p}$ adjusted on gender and age $<0.001)$.

Educational level was the most marked socio-demographic factor influencing choice of a psychiatrist rather 
Table 4: Comparison of risk factors for depression between GPs' patients and psychiatrists' patients $(n=7537)$

\begin{tabular}{|c|c|c|c|}
\hline & $\begin{array}{c}\text { GPs' patients } \\
\mathrm{n}=6104 \\
\mathrm{n}(\%)\end{array}$ & $\begin{array}{c}\text { Psychiatrists' patients } \\
n=1433 \\
n(\%)\end{array}$ & OR [IC95]* \\
\hline \multicolumn{4}{|l|}{ Serious health problem } \\
\hline (1) & $642(10.5)$ & $128(8.9)$ & 1.0 \\
\hline No & $5462(89.5)$ & $1305(91.1)$ & $0.96[0.78-1.18]$ \\
\hline \multicolumn{4}{|l|}{ Death of a person close } \\
\hline 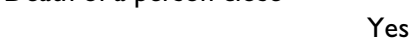 & $822(14.4)$ & $165(11.5)$ & 1.0 \\
\hline No & $5222(85.6)$ & $1268(88.5)$ & $0.86[0.72-1.03]$ \\
\hline \multicolumn{4}{|l|}{ Physical or sexual abuse } \\
\hline Fis & $164(2.7)$ & $46(3.2)$ & 1.0 \\
\hline No & $5940(97.3)$ & $1387(96.8)$ & $1.01[0.79-1.54]$ \\
\hline \multicolumn{4}{|l|}{ Pregnancy-childbirth } \\
\hline 7. & $|5|(2.5)$ & $38(2.7)$ & 1.0 \\
\hline No & $5953(97.5)$ & $1395(97.3)$ & $0.88[0.61-1.27]$ \\
\hline \multicolumn{4}{|l|}{$\begin{array}{l}\text { Divorce, separation or conflict } \\
\text { with a partner }\end{array}$} \\
\hline Yes & $1759(28.8)$ & $399(27.8)$ & 1.0 \\
\hline No & 4345 (7I.2) & $1034(72.2)$ & $0.88[0.78-1.01]$ \\
\hline \multicolumn{4}{|l|}{ Loss of job, unemployment } \\
\hline 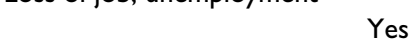 & $373(6.1)$ & 81 (5.7) & 1.0 \\
\hline No & $5731(93.9)$ & $1352(94.3)$ & $0.85[0.66-1.09]$ \\
\hline \multicolumn{4}{|l|}{ Conflict or harassment at work } \\
\hline Yes & $760(12.5)$ & $228(15.9)$ & 1.0 \\
\hline No & $5344(87.5)$ & $1205(84.1)$ & $1.23[1.05-1.45]$ \\
\hline \multicolumn{4}{|l|}{ Overwork } \\
\hline Yes & $807(13.2)$ & $178(12.4)$ & 1.0 \\
\hline No & $5297(86.8)$ & $1255(87.6)$ & $0.86[0.73-1.02]$ \\
\hline \multicolumn{4}{|l|}{ Precarious social situation } \\
\hline Yes & $173(2.8)$ & $28(2.0)$ & 1.0 \\
\hline No & 5931 (97.2) & $1405(98.0)$ & $0.65[0.43-0.97]$ \\
\hline
\end{tabular}

* GPs' patients are the reference, odd ratio adjusted on gender and on age as a quantitative variable

than a GP. The likelihood of being in the PDP group increased with the level of education.

There was no clear relationship between gender, occupation, matrimonial status, living arrangements or income and the choice to consult a psychiatrist or a GP.

\section{Clinical profile (Table 3)}

The probability of meeting DSM-IV criteria for major depressive disorder for patients identified as depressed was higher for psychiatrist consultation than for GP consultation $(94.6 \%$ v. $86 \%$, adjusted OR $=2.9)$. At the same time, past hospitalization was twice as frequent among PDPs as among PDGPs.

For all other indicators of long-standing psychiatric problems (previous suicide attempts, bipolar disorder, past depressive episodes) and of severity of the episode (CGI score) groups did not differ clearly.

Mean age at the first depressive episode was slightly younger for PDPs than for PDGPs (33.0 years $s d=11.9 \mathrm{v}$.
36.8 years $\mathrm{sd}=13.9, \mathrm{p}$ adjusted on gender and age $=$ $0.0003)$.

There were non-significant differences for co-morbidity with anxiety, alcohol dependency and somatic problems.

Role of stressful life events (Table 4)

None of the stressful events explored (death, abuse, unemployment, problem at work, difficulties with a partner, health problem) were significantly associated with the choice to consult a psychiatrist or a GP nor were other stressful situations possibly linked with increased risk of depression (recent pregnancy, precarious social situation).

\section{Care patterns (Table 5)}

The mean time lapse between the beginning of the current depressive episode and the index consultation was longer for PDPs than for PDGPs (7.1 months SD = 15.5 versus 3.8 months $\mathrm{sd}=11.0$, p adjusted on gender, age and GCI score $<0.001$ ). 
Table 5: Comparison of medical care of GPs' patients and psychiatrists' patients

\begin{tabular}{|c|c|c|c|}
\hline & $\begin{array}{c}\text { GPs' patients } \\
\text { n = 6104 } \\
n(\%)\end{array}$ & $\begin{array}{c}\text { Psychiatrists' patients } \\
\mathrm{n}=1433 \\
\mathrm{n}(\%)\end{array}$ & OR (I) [IC95] \\
\hline \multicolumn{4}{|l|}{ Time in care } \\
\hline Less than I year & $1157(19.0)$ & $911(63.8)$ & $14.96[12.37-18.10]$ \\
\hline 1 to 5 years & $1989(32.7)$ & $366(25.6)$ & $3.5 \mathrm{I}[2.87-4.29]$ \\
\hline more than 5 years & $2928(48.2)$ & $151(10.6)$ & 1.0 \\
\hline \multicolumn{4}{|l|}{$\begin{array}{l}\text { Current prescription of... } \\
\text {...antidepressant }\end{array}$} \\
\hline None & $1418(23.2)$ & $213(14.9)$ & 1.0 \\
\hline One SSRI & $4110(67.3)$ & $943(65.8)$ & $1.5 \mathrm{I}[1.28-1.78]$ \\
\hline tricyclic & $142(2.3)$ & $112(7.8)$ & $5.03[3.73-6.77]$ \\
\hline Another class & $185(3.0)$ & $98(6.8)$ & $3.77[2.8 I-5.06]$ \\
\hline 2 or more antidepressants & $249(4.1)$ & $67(4.7)$ & $1.73[1.26-2.37]$ \\
\hline \multicolumn{4}{|l|}{...anxiolytic or hypnotic } \\
\hline Yes & $2706(44.3)$ & $749(52.3)$ & $1.34[1.19-1.50]$ \\
\hline No & $3398(55.7)$ & $684(47.7)$ & 1.0 \\
\hline \multicolumn{4}{|l|}{...antipsychotic } \\
\hline Yes & $331(5.4)$ & $136(9.5)$ & $1.63[1.31-2.03]$ \\
\hline No & $5773(94.6)$ & $1297(90.5)$ & 1.0 \\
\hline \multicolumn{4}{|l|}{ Psychotherapy ** } \\
\hline Yes & $4406(72.2)$ & I $277(89.1)$ & 3.07 [2.57 - 3.67] \\
\hline No & $1698(27.8)$ & $156(10.9)$ & 1.0 \\
\hline \multicolumn{4}{|l|}{$\begin{array}{l}\text { Care also provided by another } \\
\text { health professional }\end{array}$} \\
\hline Yes & $1245(20.4)$ & $221(15.4)$ & $0.62[0.53-0.73]$ \\
\hline No & 4859 (79.6) & $1212(84.6)$ & 1.0 \\
\hline \multicolumn{4}{|l|}{$\begin{array}{l}\text { Alternative or non-conventional } \\
\text { treatment } * * *\end{array}$} \\
\hline Yes & $540(8.8)$ & $34(2.4)$ & $0.26[0.19-0.38]$ \\
\hline No & $5564(91.2)$ & $1399(97.6)$ & 1.0 \\
\hline
\end{tabular}

\footnotetext{
In bold: statistically significant odds ratio $(p<0.05)$ and less than 0.5 or higher than 2.0

* GPs' patients are the reference, odd ratio adjusted on gender, on age as a quantitative variable and on the CGI-severity score

** Supportive therapy, psychoanalytically oriented therapy or cognitive-behavioral therapy

*** Homeopathy, acupuncture, herbal medicine or mesotherapy
}

Conversely, duration of medical follow up by the practitioners was shorter for PDPs than for PDGPs.

The mean duration of the index consultation was significantly greater for PDPs $(31.3$ minutes sd $=8.8)$ than for PDGPs (23.4 minutes sd $=8.5$, $\mathrm{p}$ adjusted on gender, age and CGI <0.001).

A minority of patients did not receive antidepressants. SSRI was the class most often prescribed. Prescriptions of tricyclic and non-SSRI non-tricyclic antidepressants were both more frequent among PDPs than among PDGPs. Among patients treated with antidepressants, treatment was more longstanding for PDPs than for PDGPs. Treatment had been instated for over 6 months for $41.2 \%$ of PDPs and $25.7 \%$ of PDGPs (p adjusted on gender, age and CGI <0.001).

Prescription patterns for anxiolytics and antipsychotics (alone or in coprescription) were not significantly different in the two groups.
A large majority of patients were receiving some sort of psychotherapy with higher probability of being in psychotherapy for PDPs than for PDGPs. Regarding the different types of psychotherapy, whereas no-marked difference was observed between the groups in the frequency of supportive therapy (65.9\% for PDPs versus 68.9 for PDGPs) and cognitive-behavioural therapy (6.1\% for PDP v. $4.7 \%$ for PDGP), psychoanalytically-oriented therapy was 4 times more frequent among PDPs than among PDGPs (respectively $23.1 \%$ v $4.5 \%$ ).

The likelihood of receiving alternative therapy was lower for PDPs than for PDGPs. Collaboration between practitioner and other health professionals was slightly more frequent for PDGPs than for PDPs.

\section{Discussion \\ Main findings}

Differences between patients considered as depressed treated in general practice and those treated by community psychiatrists related mainly to certain patient socio- 
demographic characteristics (education, area of residence), with few or no differences regarding clinical profile. This pinpoints the difficulty for depressed patients from lower income categories in rural areas in accessing psychiatric care in France.

If no marked difference was found between the two types of physician for antidepressants, psychotherapy as such was clearly more frequently prescribed among psychiatrist attenders and conversely non conventional treatment (homeopathy, acupuncture, herbal medicine or mesotherapy) was more frequent among GP patients.

Differences between the two patient groups and treatment patterns appear to reflect more the organization of the French care system than the competence of providers.

\section{Limitations}

Three main limitations should be noted.

First, the participation rates of GPs $(26.8 \%)$ and psychiatrists $(19.9 \%)$ were low, and the samples non-representative in terms of regional distribution for both GPs and psychiatrists, and in terms of gender among GPs. This may have induced a selection bias with over-representation of physicians (especially GPs) with a particular interest and training in the care of depressive patients. This could lead to underestimating differences between GPs and psychiatrists with respect to patient profile and care patterns. However this does not question the existence of such differences

Second, the study design excluded depressed patients not considered as depressed by the physicians. Several studies have found that GPs often under-diagnose depression. [810] Several studies have shown that less severely depressed patients are less likely to be identified as such by GPs $[13,14]$ This could have induced a bias via underestimation of differences in clinical severity between patients seen by GPs and psychiatrists.

Third, the method relied on psychiatrists and GPs independently selecting up to five or three patients respectively, and there was no direct clinical assessment of patients, so that the results must be suspected of being subject to possible selection bias. Clinical differences between the samples could be due to differences between psychiatrists and GPs in assessment or recording, rather than to true differences between patients.

\section{Differences between depressed patients seen by GPs and those seen by psychiatrists}

Results agree with previous studies showing that attitudes toward the use of mental health services are affected by age, gender and educational status [15-18]. They show that educational status was an important factor influencing the choice by depressed subjects of consulting either a GP or a psychiatrist, the less educated patients being less inclined to use mental health services. This is surprising because in France, patients are free to refer directly to a psychiatrist whatever their socio-demographic and clinical characteristics, with good reimbursement of specialist fees.

This difference could be explained by reluctance of subjects with minor (non-psychotic) psychiatric problems to consult a psychiatrist because of social barriers. It is however much more probably related to the existence of large unprovided rural zones, and a concentration of the psychiatric offer in the more attractive large cities. Physicians in France are free to choose their practice location. It also emphasizes the saturation of the care offer in France, especially marked for psychiatric care for lack of psychiatrists, following a decrease in the number of psychiatrists trained in the last decade[19] This generates an increase in consultation fees disadvantaging poorer clients.

Regarding the clinical profiles of patients considered as depressed by GPs and by psychiatrists, the study did not reveal very marked differences, perhaps contrary to expectations However, the practitioners are very likely to have pinpointed and included the most " characteristic " patients, which means that the results need to be received with caution.

Even if GPs' patients considered as depressed tended to have less severe depressive symptoms, no significant differences were found for other indicators of severity (comorbidity, suicidal behaviour, recurrent depression). The traditional notion that GPs mainly treat "social depressive reactions" that are not "real depression" is clearly out-dated. They also spent more time in consultation with them than with their other non-depressed patients: 23 minutes against only 14-19 minutes for GP patients overall according to the Société Française de Médecine Générale.

\section{Treatment of depression}

If the well-tolerated once-a-day doses of SSRI constituted the first-line prescriptions established by both types of prescribers [20,21], psychiatrists more often prescribed tricyclic antidepressants and "new antidepressants" than GPs, perhaps because psychiatrists more often see patients after failure of the first-line of treatment (i.e. SSRI) and therefore modify therapeutic strategy, prescribing other antidepressants $[22,23]$ The longer time lapse since the beginning of antidepressant treatment for psychiatrist patients than for GP patients reinforces the probability of this hypothesis. 
Even if anxiolytics are not recommended in routine treatment for depression [24], in practice they are nevertheless often prescribed, with no differences between GPs and psychiatrists, confirming the results of a recent European study[25]

Psychotherapy (mainly supportive) was unexpectedly frequent. This result is not concordant with the fact that in France most of the GPs are not psychotherapists themselves, nor with the infrequency of double follow-up by GP and mental health professional observed in this study. It is however probably because the term "supportive psychotherapy" is understood by most GPs as a consultation that includes a mix of careful listening and personal counseling of the patient. This type of consultation takes time and may also explain the relatively long duration of GP consultations. GPs take time to listen and they do consider this sort of consultation as therapeutic in itself for depressed patients, in the same way as more structured psychotherapy. It can be added that psychotherapy has proven its efficacy in the treatment of depression, either as sole therapeutic intervention or as an adjunct to pharmacological treatment [26-29]

Non-conventional treatments are infrequent among treatments prescribed by both GPs and psychiatrists[30,31] However, these types of therapy occurred four times more frequently when a GP was consulted than when a psychiatrist was consulted. Since GPs are often the first health professional contacted for a depressive problem, they probably deal with greater patient expectations for "non aggressive" treatment than do psychiatrists. As the placebo effect is very important in mental health problems [3234], positive response to demands for non conventional treatment can be expected, even if the advantage of these treatments over placebos remains to be proved.

\section{Conclusion}

Differences between patients mainly concerned educational level and area of residence with few differences regarding clinical profile. Differences between practices of GPs and psychiatrists appear to reflect more the organization of the French care system than the competence of providers.

\section{Competing interests}

The author(s) declare that they have no competing interests.

\section{Authors' contributions}

All authors conceived of the study and participated in its design and coordination and helped to draft the manuscript. All authors read and approved the final manuscript.

\section{Acknowledgements}

to Dr Michel Faruch, Psychiatrist Toulouse France, Dr Thierry Labarthe, GP Rennes France, Dr François Liard, GP Tours, France, Dr Thierry Marquet Lundbeck France (members of scientific committee of the study).

\section{References}

I. Spitzer RL, Kroenke K, Williams JB: Validation and utility of a selfreport version of PRIME-MD: the PHQ primary care study. Primary Care Evaluation of Mental Disorders. Patient Health Questionnaire. Jama 1999, 282:1737-1744.

2. WHO: The global burden of disease. In The Global Burden of Disease: $A$ comprehensive assessment of mortality and disability from diseases, injuries, and risk factors in 1990 and projected Edited by: Murray CJ LAD. Cambridge, Harvard School of Public Health; 1996.

3. Alonso J, Angermeyer MC, Bernert S, Bruffaerts R, Brugha TS, Bryson H, Girolamo G, Graaf R, Demyttenaere K, Gasquet I, Haro JM, Katz SJ, Kessler RC, Kovess V, Lepine JP, Ormel J, Polidori G, Russo LJ, Vilagut G, Almansa J, Arbabzadeh-Bouchez S, Autonell J, Bernal M, Buist-Bouwman MA, Codony M, Domingo-Salvany A, Ferrer M, Joo SS, Martinez-Alonso M, Matschinger H, Mazzi F, Morgan Z, Morosini P, Palacin C, Romera B, Taub N, Vollebergh WA: Prevalence of mental disorders in Europe: results from the European Study of the Epidemiology of Mental Disorders (ESEMeD) project. Acta Psychiatr Scand Suppl 2004:2 I-27.

4. Sartorius N, Ustun TB, Lecrubier Y, Wittchen HU: Depression comorbid with anxiety: results from the WHO study on psychological disorders in primary health care. BrJ Psychiatry 1996, Supplement:38-43.

5. Telford R, Hutchinson A, Jones R, Rix S, Howe A: Obstacles to effective treatment of depression: a general practice perspective. Fam Pract 2002, 19:45-52.

6. Tylee A: Depression in the community: physician and patient perspective. J Clin Psychiatry 1999, 60 Suppl 7:12-6; discussion 178.

7. Goldberg D: Psychological disorders in general medical settings. Soc Psychiatry Psychiatr Epidemiol 1996, 31: I-2.

8. Jencks SF: Recognition of mental distress and diagnosis of mental disorder in primary care. Jama 1985, 253:1903-1907.

9. Wells KB, Stewart A, Hays RD, Burnam MA, Rogers W, Daniels M, Berry S, Greenfield S, Ware J: The functioning and well-being of depressed patients. Results from the Medical Outcomes Study. Jama 1989, 262:914-919.

10. Klinkman MS: The role of algorithms in the detection and treatment of depression in primary care. J Clin Psychiatry 2003, 64 Suppl 2:19-23.

II. APA: Diagnostic and statistical manual of mental disordersfourth edition. Washington, DC, American Psychiatric Association; 1994.

12. Guy W: Clinical Global Impressions. In ECDEU Assessment Manual for psychopharmacology, revised Rockville, National Institute of mental health (Ed.); 1976.

13. Williams JW], Rost K, Dietrich AJ, Ciotti MC, Zyzanski SJ, Cornell J: Primary care physicians' approach to depressive disorders. Effects of physician specialty and practice structure. Arch Fam Med 1999, 8:58-67.

14. Simon GE, VonKorff M: Recognition, management, and outcomes of depression in primary care. Arch Fam Med 1995, 4:99-105.

15. Harman JS, Schulberg HC, Mulsant BH, Reynolds CF: The effect of patient and visit characteristics on diagnosis of depression in primary care. J Fam Pract 200I, 50:1068.

16. Leaf PJ, Bruce ML, Tischler GL, Holzer CE: The relationship between demographic factors and attitudes toward mental health services. J Community Psychol 1987, 15:275-284.

17. Alonso J, Angermeyer MC, Bernert S, Bruffaerts R, Brugha TS, Bryson H, Girolamo G, Graaf R, Demyttenaere K, Gasquet I, Haro JM, Katz SJ, Kessler RC, Kovess V, Lepine JP, Ormel J, Polidori G, Russo LJ, Vilagut G, Almansa J, Arbabzadeh-Bouchez S, Autonell J, Bernal M, Buist-Bouwman MA, Codony M, Domingo-Salvany A, Ferrer M, Joo SS, Martinez-Alonso M, Matschinger H, Mazzi F, Morgan Z, Morosini P, Palacin C, Romera B, Taub N, Vollebergh WA: Use of mental health services in Europe: results from the European Study of the Epidemiology of Mental Disorders (ESEMeD) project. Acta Psychiatr Scand Suppl 2004:47-54. 
18. Kerr M, Blizard R, Mann A: General practitioners and psychiatrists: comparison of attitudes to depression using the depression attitude questionnaire. $\mathrm{Br} J$ Gen Pract 1995, 45:89-92.

19. Berland Y: Démographie des professions de santé. Volume 2005. Paris, Ministère de la santé; 2002.

20. Anderson IM, Tomenson BM: Treatment discontinuation with selective serotonin reuptake inhibitors compared with tricyclic antidepressants: a meta-analysis. Bmj 1995, 3 I 0: I 433- I 438.

21. Simon GE, VonKorff M, Heiligenstein JH, Revicki DA, Grothaus L, Katon W, Wagner EH: Initial antidepressant choice in primary care. Effectiveness and cost of fluoxetine vs tricyclic antidepressants. Jama 1996, 275: 1897-1902.

22. Ballenger JC, Davidson JR, Lecrubier $Y$, Nutt DJ, Goldberg D, Magruder KM, Schulberg HC, Tylee A, Wittchen HU: Consensus statement on the primary care management of depression from the International Consensus Group on Depression and Anxiety. J Clin Psychiatry 1999, 60 Suppl 7:54-6I.

23. Simon GE, Von Korff M, Rutter CM, Peterson DA: Treatment process and outcomes for managed care patients receiving new antidepressant prescriptions from psychiatrists and primary care physicians. Arch Gen Psychiatry 200I, 58:395-40I.

24. ANAES: Prise en charge par le médecin généraliste en ambulatoire d'un épisode dépressif isolé de l'adulte. Paris, ANAES; 2004.

25. Alonso J, Angermeyer MC, Bernert S, Bruffaerts R, Brugha TS, Bryson H, Girolamo G, Graaf R, Demyttenaere K, Gasquet I, Haro JM, Katz SJ, Kessler RC, Kovess V, Lepine JP, Ormel J, Polidori G, Russo LJ, Vilagut G, Almansa J, Arbabzadeh-Bouchez S, Autonell J, Bernal M, Buist-Bouwman MA, Codony M, Domingo-Salvany A, Ferrer M, Joo SS, Martinez-Alonso M, Matschinger H, Mazzi F, Morgan Z, Morosini P, Palacin C, Romera B, Taub N, Vollebergh WA: Psychotropic drug utilization in Europe: results from the European Study of the Epidemiology of Mental Disorders (ESEMeD) project. Acta Psychiatr Scand Suppl 2004:55-64.

26. NICE: Management of depression in primary care and secondary care. Volume 2005. London, National Institute for Clinical excellence; 2004.

27. INSERM: Psychothérapie, trois approches évaluées. In Expertises Collectives INSERM edition. Paris, ; 2004:568.

28. Thase ME, Greenhouse JB, Frank E, Reynolds CF, Pilkonis PA, Hurley K, Grochocinski V, Kupfer DJ: Treatment of major depression with psychotherapy or psychotherapy-pharmacotherapy combinations. Arch Gen Psychiatry 1997, 54:1009-1015.

29. Keller MB, McCullough JP, Klein DN, Arnow B, Dunner DL, Gelenberg AJ, Markowitz JC, Nemeroff CB, Russell JM, Thase ME, Trivedi $\mathrm{MH}$, Zajecka J: A comparison of nefazodone, the cognitive behavioral-analysis system of psychotherapy, and their combination for the treatment of chronic depression. N Engl J Med 2000, 342: I 462-I 470 .

30. Kessler RC, McGonagle KA, Zhao S, Nelson CB, Hughes M, Eshleman $S$, Wittchen HU, Kendler KS: Lifetime and I 2-month prevalence of DSM-III-R psychiatric disorders in the United States. Results from the National Comorbidity Survey. Arch Gen Psychiatry 1994, $51: 8-19$.

31. Parslow RA, Jorm AF: Use of prescription medications and complementary and alternative medicines to treat depressive and anxiety symptoms: results from a community sample. J Affect Disord 2004, 82:77-84.

32. Shapiro AK: The placebo effect in the history of medical treatment: implications for psychiatry. Am J Psychiatry 1959, I 1 6:298-304.

33. Laporte JR, Figueras A: Placebo effects in psychiatry. Lancet 1994, 344:1206-1209.

34. Moncrieff J, Wessely S, Hardy R: Active placebos versus antidepressants for depression. Cochrane Database Syst Rev 2004, I:CD0030I2.

\section{Pre-publication history}

The pre-publication history for this paper can be accessed here:

http://www.biomedcentral.com/1471-2296/7/5/prepub 